\title{
The effect of using contrast training during the pre-season period on the level of ability of muscle in junior football players
}

\author{
By \\ Dr. Ahmed Amin Ahmed El-Shafee*
}

\begin{abstract}
Contrast training is a training approach that aims at achieving the maximum level of efficiency through using various techniques of strength during the training module. In light of the importance of using diverse training approaches, the problem of lack of attention on part of coaches to the development of the ability of the muscle in junior footballers, especially during the pre-season period, the researcher seeks to identify the effects of using contrast training during the preparation period of the 2013/14 sporting season on the level of ability of the muscle in junior footballers under 17 . The researcher applied the experimental method, using a pre-test/post-test design with two groups: an experimental group and a control group, as this method is suitable to the nature of the present research. The sample was purposively selected from junior footballers under 17 years of age at Al-Ahly sporting club in Jeddah, Saudi Arabia. The research core sample consisted of 40 participants assigned equally to an experimental group and a control group. The proposed contrast training program was applied to the experimental group over a 10-week period, while the control group received the traditional general training of the team prepared by the coach throughout the application period, namely the preparation period for the 2013/14 sporting season. The research found significant differences at $\mathrm{p}$ level of 0.05 between the means of the post-test measurements of the experimental and control groups in the ability of the muscle of junior footballers tests, in favor of the experimental group. The researcher recommends that football coaches should be informed about the importance of contrast training, especially for junior players that can achieve the maximum benefit in terms of developing muscle power and ability of the muscle.
\end{abstract}

*Assistant Professor, Department of Teaching Methods, Training, and Practical Education, Faculty of Physical Education, El-Sadat City University 


\section{Introduction:}

Developed countries seek to invest in sports training as a science and basic means for developing and advancing athletes' physical, skills, functional, psychological, and intellectual abilities, hence attaining sporting achievements. Sports training relies on various principles, goals, and methods that enable it to expand and employ new findings of related sciences. This allows the continuous updating of the approaches used in implementing the training processes, and ensures the best outcomes.

Contrast training is one of the approaches that aim at attaining the maximum level of efficiency by using diverse power techniques within a single training module. It also seeks to find high levels of physical responses and adaptations, which help indirectly in developing the athlete's overall training condition (Al-Aly \& Shaghaty, 2010: 88-89).

McGregor (2006) points out that contrast training is one of modern training methods in sports. Many studies considered the effects of contrast training on physical and physiological variables in youth and adult players (McGregor, 2006: 125).

Sigmon (2008) demonstrates that when training uses a variety of training load components and exercises performance techniques, then it is called contrast training, as sets of weight exercises and plyometrics are used alternately (Sigmon, 2005: 41).

Hickson et al. (2000), Bastiaans et al. (2001), and Levin (2007) agree that using weight training or plyometrics separately has its pros and cons, whereas using various sets of exercises by combining both methods (weight training and plyometrics) may lead to better outcomes in developing the skills and physical levels of athletes. This is called contrast training (Hickson et al., 2000: 540; Bastiaans et al., 2001: 79; Levin, 2007: 64).

El-Sokkary and Breika (2001) add that most sport teams are subjected to a variety of training methods that aim at exerting players' maximum energy. This amount of training repetitions may lead to repeated injuries due to overuse. It may also result in some psychological problems, especially emotions related to steady performance and boredom. In order to overcome this problem, the coach should be able to combine various exercises within each training modules, so as moves similar to the performance model related to the performed activity are used, such as speed, ability, and endurance. If the coach could go beyond the traditional methods to more effective methods, he/she would increase the training stimuli, add more motivation and enjoyment, and diminish boredom (El-Sokkary \& Breika, 2001: 22-23).

Contrast training aims at avoiding a monotonous training, as the training changes by using light and heavy weights subsequently, and contrast can be achieved by alternating loads (maximum strength, strength-endurance, and speed-strength) in an explosive manner or by altering the load level, the type of muscle contraction and tension, or from weight training to plyometrics (Abdel Maqsoud, 1997: 317-319).

Reviewing the findings of several previous studies (e.g. Duthie et al, 2000; El-Sayed, 2004; Fletcher \& Hartwell, 2004; Smilios et al., 2005; Clark et al., 2006; Ibrahim, 2009; Said et al., 2011; Jamal, 2011; Jamal, 2013; Abul Maaty, 2016; El-Tanahy, 2016), it was found that they agree that employing weight training and plyometrics in a contrast manner contributes effectively in developing physical abilities in general, and ability of the muscle in particular.

Football training relies on alternating work and rest intervals, which requires a high level of physical abilities, especially ability of muscle, which enable the footballer to perform the technical and tactical aspects more effectively throughout the match.

Additionally, Hammad (2000) notes that the amount of exercises directed to develop the muscular ability and strength in junior players can be increased gradually from 14 to 16 years old, while avoiding fixed exercises and heavy-weight slow doses. The amount of exercises directed toward the different types of strength development can be increased 
without any worries after 16 years of age. However, it is important to apply the principles of training load progression (Hammad, 2000: 20).

Modern football requires that the player has a high level of ability of the muscle which enables the player to overcome his opponent, in terms of performance and pressure in case the technical level is similar. The researcher noticed this through his experience in working with age groups. He noticed a lack of attention to training the ability of the muscle in an adequate and guided manner, despite its importance, by the technical staff, especially in junior players.

The researcher focused on the junior age group (under 17 years of age), which is an exceptional period for acquiring the different types of muscular strength, especially during the preparation period for the sporting season, and ensure the contribution in developing the overall training condition on the one hand, and increasing the ability to cope with muscular injuries on the other. Thus, junior players become more ready and prepared to go through the competition period.

According to the aforementioned review, and in light of the importance of diversifying the used training approaches, and the problem of coaches' lack of attention to the development of junior footballers' ability of muscle especially during the preparation period for the sporting season, the researcher seeks to identify the effect of using contrast training during the preparation period for the sporting season 2013/2014 on the level of ability of the muscle in junior footballers under 17 years of age.

\section{Research Objectives:}

1. Designing a contrast training program (weight training and plyometrics) during the preparation period of junior footballers.

2. Identifying the effect of using contrast training during the preparation period on the level of junior footballers' ability of muscle.

\section{Research Hypotheses:}

1. Statistically significant differences exist between the Means of control group's pre-test and post-test measurements in the junior footballers' ability of muscle tests, in favor of the post-test measurements.

2. Statistically significant differences exist between the Means of experimental group's pre-test and post-test measurements in the junior footballers' ability of muscle tests, in favor of the post-test measurements.

3. Statistically significant differences exist between the Means of the control and experimental groups' post-test measurements in the junior footballers' ability of muscle tests, in favor of the experimental group.

4. There are differences between the control and experimental groups' change rates in the Means of post-test measurements in the junior footballers' ability of muscle tests, in favor of the experimental group.

\section{Research Terms:}

1. Contrast Training: is a form of training of alternating the performance of high-intensity weight training set followed immediately by plyometric exercises of different intensities, while taking into consideration that the working muscle groups and the motion pathways of plyometric and weight exercises are similar (McGregor, 2006: 125).

2. The ability of the muscle: is the ability of muscles to produce high levels of strength for short intervals (explosive power). The ability of the muscle can be increased by strength training. The ability of muscle is one of the most vital and crucial elements in various daily physical activities as well as all competitive sports (Breika \& El-Bedewy, 2005: 17-18). 


\section{Research Procedures:}

\section{A. Research Method:}

The researcher applied the experimental method, using a two-group (a control group and an experimental group) pre-test/post-test measurement design, as it is suitable to the nature of the present research.

\section{B. Participants:}

The research sample was purposefully selected from junior footballers under 17 years of age at Al-Ahly sporting club in Jeddah, Saudi Arabia, who are registered with the Saudi Arab Football Association for the sporting season 2013/14. The research core sample consisted of 40 junior footballers, who were divided into two groups:

- An experimental group (20 players), to which the proposed training program, prepared by the researcher, using contrast training (weight training and plyometrics) was applied during the preparation period for the sporting season 2013/14.

- A control group (20 players), to which the traditional training program, prepared by the team's coach, was applied during the preparation period for the sporting season 2013/14. Additionally, 10 junior footballers from the same team (under 17 years of age) and not included in the research core sample were selected for the undifferentiated group, as well as 10 young players (under 19 years of age) at Al-Ahly club for the differentiated group of the exploratory study.

1. The normality of the research core sample's data:

The researcher checked the normality of the research core sample's data (composed of 40 players) in terms of growth variables (age, height, and weight), training years, as shown in Table 1 and appendix 1/A.

\section{Data collection instruments and devices:}

The researcher used the following instruments and devices to collect data:

1. Tools and devices:

\begin{tabular}{|c|c|c|}
\hline * A Restameter and a scale & $*$ football field & * mattresses \\
\hline $\begin{array}{c}\text { * Olympic bar and different } \\
\text { weights }\end{array}$ & $\begin{array}{l}\text { * weightlifting } \\
\text { gymnasium }\end{array}$ & * stopwatch \\
\hline $\begin{array}{l}\text { * Medicine ball of various } \\
\text { weights }\end{array}$ & * 2-kilogram dumbbells & $\begin{array}{l}\text { measuring } \\
\text { tape }\end{array}$ \\
\hline * Stackable plyo-boxes & * Swedish benches & * adhesive tape \\
\hline * Hurdles of different heights & * cones and hoops & * whistle \\
\hline $\begin{array}{c}* \text { Football goals of different } \\
\text { sizes }\end{array}$ & $\begin{array}{c}\text { * Slalom poles and } \\
\text { marker cones }\end{array}$ & * chalk \\
\hline
\end{tabular}

2. Used tests:

a. Growth rates: *age: according to birth date (approximated to the nearest year)

* Height: as measured by the Restameter, in centimeters

* Weight: as measured by a scale in kilograms.

b. Training years (to the nearest year)

c. The ability of the muscle under research tests: appendix 2

In determining the ability of the muscle under research tests, the researcher drew upon the agreement of several references (Rizqallah, 1994; Hassanein, 1995; Khater \& El-Beik, 1996; Abul Majd \& El-Nemaki, 1997; Salamah, 2000; and Farahat, 2005) that the following tests are used in measuring the level of ability of the muscle in many sports activities, including football:

- Sargent vertical jump, measured in centimeters.

- Standing long jump, measured in meters.

- Sit-ups, measured by repetitions. 
- Pushing a medicine ball, measured in meters.

\section{d. Data entry and test results forms: appendix 3}

D. Exploratory Studies:

They were conducted from 14-22 August 2013 with the exploratory study sample. The first exploratory study resulted in ensuring that:

- the scientific coefficients (validity and reliability) of the used tests are adequate.

- the tools and devices used in the research are valid.

- training the assistants (appendix 4) on how to apply and record the results of the tests under research.

- finding possible errors that can occur during administering the tests so they can be avoided in the main study.

1. The first exploratory study:

a. Calculating the validity coefficients of the tests under research:

The validity of the tests under research was calculated by finding the discriminant validity by applying them to the exploratory study's sample which was divided into two groups:

- The first group was the undifferentiated group and consisted of 10 junior footballers under 17 years of age.

- The second group was the differentiated group and consisted of 10 young footballers under 19 years of age.

Table 2 shows the significance of differences between the measurements of the two groups in the tests under research. Appendix 1/B

\section{b. Calculating the reliability coefficients of the tests under research:}

The reliability coefficients of the ability of muscle tests under research by applying the testretest method to the undifferentiated group within the exploratory study's sample that consisted of 10 junior players under 17 . The researcher considered the validity results of this group as the test results, then conducted a retest under the same conditions and with the same instructions after one week. Table 3 shows the correlation coefficients between the test and retest. Appendix 1/C

\section{The second exploratory study:}

It was conducted from 24-27 August 2013 to the exploratory sample of 10 junior players under 17, which is the same age group of the main experiment. The results of the second exploratory study confirmed that:

- The settings allocated for conducting the main experiment are suitable.

- The used training tools, training models that will be applied within the contrast training program under research are valid.

- The appropriate training loads for the research sample's level were structured (load intensity, number of sets and exercises, rest intervals).

- The maximum weight, medicine balls, and maximum height of the stackable plyo-boxes were determined for each player as follows:

$\checkmark$ After the warm-up the player performs consecutive trials with appropriate rest intervals to determine the maximum weight the player can lift. The following should be taken into consideration:

- The Olympic bar (220-cm long, and weighs 20-kg)

- A 5-kg weight is added in each new trial to lift the maximum weight.

- Weightlifting in each trial is done once, without stopping during the lift.

- The progression in weight increase takes place in light of the aforementioned steps, taking into account that one correct repetition should be done each time until the maximum weight the player can lift once is reached. 
The junior player performs the deep jump above the multiple-height stackable plyoboxes, while changing heights so that the suitable starting heights of the wooden boxes used in plyometrics can be determined.

The second exploratory study resulted in determining the starting height of the stackable plyo-boxes used in the plyometric exercises at $35 \mathrm{~cm}$. It also determined the medicine ball starting weight at $3 \mathrm{~kg}$, and the dumbbells starting weight at $2 \mathrm{~kg}$.

E. The proposed contrast training program:

1. The program's goal:

The proposed program aims at developing the ability of muscle in junior footballers under 17 years of age.

2. Program development basics:

When developing the content of the training program, the researcher took the following basics into consideration:

- The content of the program should be suitable to its objectives and the level of the used sample.

- Weight training principles (specificity, overload, adaptation, progression).

- Individual differences of junior players when selecting the program exercises (content).

- Determining the suitable (interval, daily, weekly) training load for the sample.

- The duration of the program was 10 weeks, three training daily modules per week.

- The duration of the daily training module was 110 minutes divided into: 15 minutes physical conditioning (warm-up), 90 minutes the main part, and 5 minutes cool down (final part).

- The duration of contrast training within the experimental group's daily training module was 20-30 minutes.

- The gradual increase in the training load in accordance with the sample's age and level.

- Paying attention to flexibility and stretching exercises in the preparatory part of the training module to condition the working muscles for performance, as well as during the rest intervals between sets.

- Weight exercises are performed first then followed by plyometrics.

- Weight training and plyometrics are used alternately within each daily training module in accordance with the general goals of the preparation period, and also to avoid any boredom of the single routine of muscle work.

After reviewing several previous scientific references and studies (Sayed, 1993; Hammad, 1996; Abdel Maqsoud, 1997; El-Shafee, 2000; El-Nemr, 2000; El-Besaty, 2001; Abou Abdou, 2007; El-Beik, 2008; Ibrahim, 2009; Said, Mohamed, \& Hassan, 2011; Abul Maaty, 2016; El-Tanahy, 2016) that considered planning contrast training, weight training, and plyometrics training programs and their training load, the researcher could plan the contrast training program under research, and determine the contents of its training loads. Appendix 5 , shows the overall plan of the team's training program.

3. Content of the Program:

The researcher surveyed the scientific references and studies that addressed designing contrast training, weight training, and plyometric training programs (Abdel Dayem, 1993; El-Nemr \& El-Khatib, 1996; Shehata, 1997; Radwan \& Mansour, 1999; El-Nemr \& ElKhatib, 2000; Hammad, 2000; Breika \& El-Bedeiwy, 2005; Abou Abdou, 2008; Ismail, 2010), thus he could determine the working muscle groups during the physical and skills performance of junior footballers. Based on this, he developed the program content. Appendix 6 outlines both the weight training and plyometrics contents of the contrast training program.

F. Plan of implementing the main research experiment: 
The plan of the main research experiment was implemented under the supervision of the researcher and his assistants. Standardization of the conditions during the pre-test and posttest measurements was taken into consideration. The implementation plan included the following:

1. Pre-test measurements:

Pre-test measurements of both the experimental group and the control group in the ability of the muscle of the studied junior footballers under 17 tests were conducted on 29-30 August 2013. The researcher also calculated the equivalence of the experimental and control groups in the tests under research. Table 4 outlines this. Appendix 1/D

2. Applying the proposed contrast training program:

The team's general training program was applied to both the experimental and control groups during the preparation period of the 2013/14 sporting season. The researcher and his assistants applied the content of the (proposed) contrast training program (weight training and plyometrics) to the experimental group over 10 weeks. Participants received three daily training modules each week. Meanwhile, the control group was trained according to the (traditional) general training program prepared by the coach throughout the implementation period from 1 September to 7 November 2013. Appendix 7 outlines sample of a daily training module of the team's general training program (the content application method to the control and the experimental groups).

3. Post-test Measurements:

The post-test measurements of the experimental and control groups in the ability of muscle of junior footballers under 17 tests were conducted on 8-9 November 2013.

G. Statistical treatment:

The SPSS software was used for processing the data. The following statistical techniques were used: the Mean, standard deviation, median, skewness coefficient, $t$ test, Pearson simple correlation, change rates by percentage. The researcher accepted statistical significance to be at 0.05 .

\section{Results and Discussion:}

1. Results and discussion of the first hypothesis:

Table 5

Significance of differences between the control group's pre-test and post-test measurements in the ability of the muscle of junior footballers tests $\quad N=20$

\begin{tabular}{c|c|c|c|c|c|c|c}
\hline \hline $\begin{array}{c}\text { The ability of the } \\
\text { muscle tests under } \\
\text { research }\end{array}$ & \multirow{2}{*}{$\begin{array}{c}\text { Measuremen } \\
\mathrm{t} \text { unit }\end{array}$} & \multicolumn{2}{|c|}{$\begin{array}{c}\text { Pre-test } \\
\text { measurement }\end{array}$} & \multicolumn{2}{|c|}{$\begin{array}{c}\text { Post-test } \\
\text { measurement }\end{array}$} & $\begin{array}{c}\text { Difference } \\
\text { between } \\
\text { means }\end{array}$ & $\begin{array}{c}\text { Calcu } \\
\text { lated } t \\
\text { value }\end{array}$ \\
\cline { 3 - 8 } & $\mathrm{M}$ & $\mathrm{SD} \pm$ & $\mathrm{M}$ & $\mathrm{SD} \pm$ & & \\
\hline \hline $\begin{array}{c}\text { Sargent vertical } \\
\text { jump }\end{array}$ & $\mathrm{cm}$ & 32.46 & 3.24 & 38.17 & 2.98 & 5.71 & $9.08^{*}$ \\
\hline Standing long jump & $\mathrm{m}$ & 1.88 & 0.30 & 2.19 & 0.22 & 0.31 & $5.83^{*}$ \\
\hline Sit-ups & $\begin{array}{c}\text { Repetition } \\
\mathrm{s}\end{array}$ & 14.50 & 1.74 & 16.63 & 1.57 & 2.13 & $6.36^{*}$ \\
\hline $\begin{array}{c}\text { Pushing a medicine } \\
\text { ball }\end{array}$ & $\mathrm{m}$ & 6.54 & 0.70 & 7.25 & 0.57 & 0.71 & $5.51^{*}$ \\
\hline \hline
\end{tabular}

* tabular $t$ value at statistical significance $19, p$ level $0.05=1.729$

Table 5, and its graph shown in figure 1 in Appendix 8, shows that there are statistically significant differences at $\mathrm{p}$ level of 0.05 between the means of the pre-test and post-test measurements of the control group in terms of the ability of muscle of junior footballers tests, in favor the post-test measurements.

The researcher attributes the differences between the means of the control group's pre-test and post-test measurements in the ability of muscle tests to the team's general training 
program which was applied to the control group. The program included allocating time for training the general and specific physical abilities during the implementation of the program in the preparation period for the sporting season 2013/14. Moreover, the contents of the program involved various physical exercises and structuring the training load in accordance with the players' abilities. The duration of the control group's program, namely the preparation period that spanned over 10 weeks, was sufficient to develop the ability of the muscle. This is consistent with Baechle and Earle's (2000) remark that the duration required for developing physical abilities is six to eight weeks of 3-5 daily training modules per week (Baechle \& Earle, 2000: 435).

This is also consistent with the findings of Abdullah (2003), El-Sayed (2004) and Jamal (2011) that training programs that were applied to control groups resulted in the development of physical abilities, especially the ability of muscle. This was shown by the statistically significant differences between the means of the control group's pre-test and post-test measurements in these studies.

The aforementioned discussion demonstrates that the first hypothesis that reads: "Statistically significant differences exist between the Means of control group's pre-test and post-test measurements in the junior footballers' ability of muscle tests, in favor of the posttest measurements" has been supported.

2. Results and discussion of the second hypothesis:

\section{Table 6}

Significance of differences between the experimental group's pre-test and post-test

\begin{tabular}{c|c|c|c|c|c|c|c|c} 
measurements in the ability of the muscle of junior footballers tests & \multicolumn{2}{|c|}{$\boldsymbol{N}$ ost-test } \\
\hline \hline $\begin{array}{c}\text { The ability of the } \\
\text { muscle tests } \\
\text { under research }\end{array}$ & $\begin{array}{c}\text { Measu } \\
\text { rement } \\
\text { unit }\end{array}$ & \multicolumn{2}{|c|}{$\begin{array}{c}\text { Pre-test } \\
\text { measurement }\end{array}$} & \multicolumn{2}{|c|}{$\begin{array}{c}\text { Difference } \\
\text { measurement } \\
\text { between } \\
\text { means }\end{array}$} & $\begin{array}{c}\text { Calcul } \\
\text { ated } t \\
\text { value }\end{array}$ \\
\hline \hline $\begin{array}{c}\text { Sargent vertical } \\
\text { jump }\end{array}$ & $\mathrm{cm}$ & 32.10 & 3.39 & 44.25 & 3.05 & 12.15 & $18.65^{*}$ \\
\hline $\begin{array}{c}\text { Standing long } \\
\text { jump }\end{array}$ & $\mathrm{m}$ & 1.85 & 0.25 & 2.50 & 0.17 & 0.65 & $15.05^{*}$ \\
\hline Sit-ups & $\begin{array}{c}\text { Repeti } \\
\text { tions }\end{array}$ & 14.18 & 1.55 & 18.30 & 1.33 & 4.12 & $14.12^{*}$ \\
\hline $\begin{array}{c}\text { Pushing a } \\
\text { medicine ball }\end{array}$ & $\mathrm{m}$ & 6.42 & 0.64 & 7.86 & 0.55 & 1.44 & $11.95^{*}$ \\
\hline \hline
\end{tabular}

* tabular $t$ value at statistical significance $19, p$ level $0.05=1.729$

Table 6, and its graph shown in figure 2 in Appendix 8, shows that there are statistically significant differences at $p$ level of 0.05 between the experimental group's pre-test and posttest measurements in terms of the ability of muscle of junior footballers tests, in favor of the post-test measurements.

The researcher attributes the differences between the experimental group's pre-test and posttest measurements in the ability of muscle tests to the effectiveness of the contrast training program applied to the experimental group, which involved performing sets of high-intensity weight training followed immediately by plyometric exercises at varied intensities. It was taken into consideration that the working muscle groups and motion path in the exercises (program content) are similar in the plyometric exercises and weight training.

The contrast training program also combined the advantages of weight training and plyometrics. It took into consideration the principles of weight training, structuring training loads in a scientific manner that took individual differences of the experimental group participants into account, and the gradual increase of training load in accordance with the under 17 participants' age group. Furthermore, the program content included stretching and flexibility exercises that were performed during the active rest intervals between the weight training and plyometrics. 
Hickson et al. (2000) pointed out that contrast training had several effects. Contrast training avoids a monotonous nature of training which leads to some negative outcomes such as lack of motivation and boredom, as it increases the motivation to perform seriously and prevents players' boredom. It also solves the problem of reaching a plateau in the development of physical abilities. Additionally, it provides a better opportunity to perform larger training amounts within the training module, as the equipment and devices used in training are diverse.

This is consistent with the findings of El-Safy (2009), Said et al. (2011), Jamal (2013), Abul Maaty (2016), and El-Tanahy (2016), who found that contrast training (weight training and plyometrics) is effective in developing the athlete's physical abilities in general and the ability of the muscle in particular.

The aforementioned discussion shows that the second hypothesis, which reads: "Statistically significant differences exist between the Means of experimental group's pre-test and posttest measurements in the junior footballers' ability of muscle tests, in favor of the post-test measurements" has been supported.

3. Results and discussion of the third hypothesis:

Table 7

Significance of differences between the control and experimental groups' post-test measurements in the ability of the muscle of junior footballers tests $N 1=N 2=20$

\begin{tabular}{c|c|c|c|c|c|c|c}
\hline \hline $\begin{array}{c}\text { The ability of the } \\
\text { muscle tests under } \\
\text { research }\end{array}$ & \multirow{2}{*}{$\begin{array}{c}\text { Measurement } \\
\text { unit }\end{array}$} & \multicolumn{2}{|c|}{ Control group } & \multicolumn{2}{|c|}{$\begin{array}{c}\text { Experimental } \\
\text { group }\end{array}$} & $\begin{array}{c}\text { Difference } \\
\text { between } \\
\text { means }\end{array}$ & $\begin{array}{c}\text { Calculated } t \\
\text { value }\end{array}$ \\
\cline { 3 - 8 } & $\mathrm{M}$ & $\mathrm{SD} \pm$ & $\mathrm{M}$ & $\mathrm{SD} \pm$ & 6.08 & $9.98^{*}$ \\
\hline \hline Sargent vertical jump & $\mathrm{cm}$ & 38.17 & 2.98 & 44.25 & 3.05 & 6.08 \\
\hline Standing long jump & $\mathrm{m}$ & 2.19 & 0.22 & 2.50 & 0.17 & 0.31 & $7.80^{*}$ \\
\hline Sit-ups & Repetitions & 16.63 & 1.57 & 18.30 & 1.33 & 1.67 & $5.68^{*}$ \\
\hline $\begin{array}{c}\text { Pushing a medicine } \\
\text { ball }\end{array}$ & $\mathrm{m}$ & 7.25 & 0.57 & 7.86 & 0.55 & 0.61 & $5.39^{*}$ \\
\hline \hline
\end{tabular}

$*$ tabular $t$ value at statistical significance $38, p$ level $0.05=1.684$

Table 7, and its graph shown in figure 3 in Appendix 8, show statistically significant differences at $p$ level of 0.05 between the control and experimental groups' post-test measurements in the ability of muscle of junior footballers tests, in favor of the experimental group's post-test measurements.

The researcher attributes the differences between the post-test measurements of the control and experimental groups in the ability of muscle tests to the effectiveness of the control group's program that used contrast training and relies on combining weight training and plyometrics; using diverse training techniques, which resulted in developing the ability of leg muscles, abdominal muscles, and arm muscles; and employing flexibility and stretching exercises in the active rest intervals between different sets of exercises. Meanwhile, the control group's program included the regular physical exercises. Therefore, the junior footballers of the experimental group outperformed their counterparts in the control group in the ability of muscle tests under research.

This is consistent with the findings of El-Sayed (2004), El-Safy (2009), Said et al. (2011), Jamal (2013), and Abul Maaty (2016) that the use of contrast training within the training modules is important during the athlete's preparation period, as it combines the advantages and strengths of resistance training (weight training and plyometrics) which helps develop their physical abilities in general and ability of muscle in particular.

The aforementioned discussion demonstrates that the third hypothesis which reads: "Statistically significant differences exist between the Means of the control and experimental groups' post-test measurements in the junior footballers' ability of muscle tests, in favor of the experimental group" has been supported.

4. Results and discussion of the fourth hypothesis: 


\section{Table 8}

Change rates in the post-test measurements of the control and experimental groups' in the ability of the muscle of junior footballers tests $N 1=N 2=20$

\begin{tabular}{c|c|c|c|c|c|}
\hline $\begin{array}{c}\text { The ability of the muscle } \\
\text { tests under research }\end{array}$ & $\begin{array}{c}\text { Measurement } \\
\text { unit }\end{array}$ & $\begin{array}{c}\text { Control group's } \\
\text { post-test } \\
\text { measurement }\end{array}$ & $\begin{array}{c}\text { Experimental } \\
\text { group's post-test } \\
\text { measurement }\end{array}$ & $\begin{array}{c}\text { Difference } \\
\text { between } \\
\text { means }\end{array}$ & $\begin{array}{c}\text { Improve } \\
\text { ment rate } \\
\%\end{array}$ \\
\hline \hline Sargent vertical jump & $\mathrm{cm}$ & 38.17 & 44.25 & 6.08 & $15.93 \%$ \\
\hline Standing long jump & $\mathrm{m}$ & 2.19 & 2.50 & 0.31 \\
\hline Sit-ups & Repetitions & 16.63 & 18.30 & $14.16 \%$ \\
\hline Pushing a medicine ball & $\mathrm{m}$ & 7.25 & 7.86 & 0.61 & $10.04 \%$ \\
\hline \hline
\end{tabular}

Table 8, and its graph shown in figure 4 in Appendix 8, shows differences in the change rates in the post-test measurements of the control group and the experimental group in the ability of muscle of junior footballers tests in favor of the experimental group.

The researcher attributes these differences to the effectiveness of the experimental group's program compared to the control group's program. This further supports the findings in table 7, which pointed out the preeminence of the experimental group participants' measures over the control group's measurements in the ability of muscle tests under research.

The change rates in the ability of muscle tests were in favor of the experimental group in the following order: Sargent vertical jump test came first (15.93\%), standing long jump test came second $(14.16 \%)$, sit-ups came third $(10.04 \%)$, while pushing a medicine ball came fourth $(8.41 \%)$. The researcher explains the order of change rates that it was in light of directing the training volumes and the type of exercises used within the training programs of the two research groups in correspondence with the working muscle groups in the technical and motor performance of football activities, which relies in turn on the muscle groups of the leg, followed by the abdomen, then the arms.

The aforementioned discussion shows that the fourth hypothesis, which reads: "There are differences between the control and experimental groups' change rates in the Means of posttest measurements in the junior footballers' ability of muscle tests, in favor of the experimental group" has been supported.

\section{Conclusions:}

In light of the research objectives, used method, and the results of the statistical analysis, the researcher concludes the following:

1. Statistically significant differences, at $p$ level of 0.05 , exist between the Means of control group's pre-test and post-test measurements in the junior footballers' ability of muscle tests, in favor of the post-test measurements.

2. Statistically significant differences, at $p$ level of 0.05 , exist between the Means of experimental group's pre-test and post-test measurements in the junior footballers' ability of muscle tests, in favor of the post-test measurements.

3. Statistically significant differences exist, at $p$ level of 0.05 , between the Means of the control and experimental groups' post-test measurements in the junior footballers' ability of muscle tests, in favor of the experimental group.

4. There are differences between the control and experimental groups' change rates in the Means of post-test measurements in the junior footballers' ability of muscle tests, in favor of the experimental group.

\section{Recommendations:}

Within the limitations of the used research procedures and findings, the researcher makes the following recommendations:

1. Football coaches should be informed about the importance of contrast training, especially for junior footballers who can benefit the most in terms of developing muscle ability and strength. 
2. Using various training approaches instead of relying on a single approach is important for improving the ability of the muscle.

3. The basics of building contrast training programs and determining the training loads should be taken into account in accordance with the time span and the implementation period of the program during the sporting season.

4. Attentions should be paid to Flexibility and agility exercises when implementing contrast training programs to avoid the effect of strength training on the level of joint flexibility.

5. Studies should be conducted to identify the effect of contrast training on the physical and physiological abilities of footballers throughout the different periods of the sporting season.

6. Similar studies should be conducted in other sports and with other age groups.

\section{References:}

1. Abdel Dayem, M. (1993): Physical preparation and weight training program, Cairo: AlAhram Press

2. Abdel Maqsoud, E. (1997): Sports training theories: Strength training and physiology, Cairo: Al-Kitab publishing center

3. Abdullah, M.A. (2003): The effect of weight training and plyometrics on some physical, skills, and physiological variables in handball players, Unpublished Ph.D. Thesis, Faculty of Physical Education, Menia University

4. Abou Abdou, H.E. (2007): Modern trends in football planning and training, $2^{\text {nd }}$ ed., Alexandria: Al-Ish'aa'a Technical Bookstore and Print house

5. Abou Abdou, H.E. (2008): Physical preparation of the football player, Alexandria: AlIsh'aa'a Technical Bookstore and Print house

6. Abul Maaty, H.K. (2016): The effect of using contrast training for developing some specific physical abilities on the digital level of discus throw, Journal of Sport Sciences Applications, no. 88, Faculty of Physical Education for Boys, Alexandria University

7. Abul Majd, A.A. \& El-Nemaky, J.I. (1997): Planning education and training programs of children and junior footballers, Cairo: Al-Kitab publishing center

8. Breika, M.J. \& El-Bedeiwy, I.F. (2005): An integrated system of muscle power and muscle endurance training, Alexandria: Monshat Al-Maarif

9. El-Aly, H.A. \& Shaghaty, A.F (2010): Sport training strategies, methods, and approaches, Baghdad: Al-Nour Bookstore

10. El-Beik, A.F. (2008): Basics of football players, Alexandria: Monshat Al-Maarif

11. El-Besaty, A.A. (2001): Functional physical preparation in football: Planning, training, and measurement, Alexandria: Al-Jamia Al-Jadida publishing house

12. El-Nemr, A.A. (2000): Sports training and weight training for junior players, Cairo: AlOstatha for sport books

13. El-Nemr, A.A. \& El-Khatib, N. (1996): Weight training: Designing strength programs and planning the training season, Cairo: Al-Kitab Publishing Center

14. El-Nemr, A.A. \& El-Khatib, N. (2000): Physical preparation and weight training of youth players, Cairo: Al-Kitab Publishing Center

15. El-Sayed, I.E. (2004): The effect of contrast training using weights and plyometrics on some specific physical abilities and the digital level of long jump athletes, Unpublished Ph.D. Thesis, Faculty of Physical Education, Tanta University

16. El-Shafee, A.A. (2000): Developing technical preparation of junior footballers, Unpublished M.A. Thesis, Faculty of Physical Education for Boys, Zagazig University

17. El-Sokkary, K. \& Breika, M.J. (2001): The integrated training series, Part I, Alexandria: Monshat Al-Maarif 
18. El-Tanahy, N.A. (2016): The effectiveness of contrast training on the level of some specific motor abilities and determinants of the offensive activity in (Kumite) actual fight competition players, Applications of Sport Sciences Journal, no. 88, Faculty of Physical Education for Boys, Alexandria University

19. Farahat, L.E. (2005): Measuring and testing in education, $2^{\text {nd }}$ ed., Cairo: Al-Kitab publishing center

20. Hammad, M.I. (1996): Sports training of the two sexes from childhood to adolescence, Cairo: Dar Al-Fikr Al-Arabi

21. Hammad, M.I. (2000): Basics of developing children's muscle power by resistance, Cairo: Al-Kitab Publishing Center

22. Hassanein, M.S. (1995): Measurement and Evaluation in Physical Education and Sport, $3^{\text {rd }}$ ed., Cairo: Dar Al-Fikr Al-Arabi

23. Ibrahim, M.S. (2009): The effect of using contrast training on some physical and skills variables in basketball players, Unpublished M.A. Thesis, Faculty of Physical Education for Boys, Menia University

24. Ismail, M.A. (1998): Muscle power training and weight programs for youngsters, Alexandria: Monshat Al-Maarif

25. Ismail, M.A. (2010): Muscle power training in basketball, Alexandria: Monshat AlMaarif

26. Jamal, M. (2011): The effect of using contrast training on developing ability of muscle and leaping in 13-15-year-old male basketball players, The Scientific Journal of Physical Activities and Sports Sciences and Technologies, no. 8, Physical Education and Sports Institute, Mostaganem University, Algeria

27. Jamal, M. (2011): The effect of contrast training using weights and plyometrics on developing some physical qualities and improving the jump shot in 13-15-year-old handball players, Theories and Practices Journal, no. 77, Part I, Faculty of Physical Education, Alexandria University

28. Khater, A.M. \& El-Beik, A.F. (1996): Measurement in the field of sport, $4^{\text {th }}$ ed., Cairo: Dar Al-Kitab Al-Hadith

29. Radwan, M.N. \& Mansour, A.M. (1999): 99 exercises for muscle power and motor flexibility for all sporting activities, Cairo: Al-Kitab publishing center

30. Rizkallah, B. (1994): Physical and skills requirements of the football player, Alexandria: Dar Al-Maarif

31. Said, S.M., Mohamed, N.Q. \& Hassan, M.M. (2011): The effect of contrast training on the development of the legs muscle power in basketball players, Faculty of Basic Education Journal, vol. 11, no. 2, Mosul, Iraq

32. Salama, I.A. (2000): A practical introduction to measurement in fitness, Alexandria: Monshat Al-Maarif

33. Sayed, M.S. (1993): Physical preparation and weight training programs, Cairo: AlAhram Press

34. Shehata, M.I. (1997): Weight training, Alexandria: Monshat Al-Maarif

35. Baechle, T., Earle, R., (2000): Essentials of strength training and conditioning $2^{\text {nd }} \mathrm{ed}$, Human Kinetics

36. Bastiaans, J.J., Van Diemen, A.B., Veneberg, T., \& Jeukendrup, A.E. (2001): The effects of replacing a portion of endurance training by explosive strength training on performance in trained cyclists, European Journal of Applied Physiology, 86:79-84

37. Clark, R.A., Bryant, A.L., \& Reaburn, P. (2006): The acute effects of a single set of contrast preloading on a loaded countermovement Jump training session, Journal of Strength and Conditioning Research, 20(1), pp:162-6 
38. Duthie, G.M., Young, W.B. \& Aitken, D.A. (2002): The acute effects of heavy loads on jump squat performance: an evaluation of the complex and contrast methods of power development, Journal of Strength and Conditioning Research, 16(4), pp:530538

39. Fletcher, I.M., \& Hartwell, M. (2004): Effect of an 8-week combined weights and plyometrics training program on golf drive performance, Journal of Strength and Conditioning Research, Vol. 18. No. 1, pp:59-62

40. Hickson, R.C., et al. (2000): Potential for strength and endurance training to amplify endurance performance, Journal of Applied Physiology, 65: 2285-2290

41. Levin, G.T. (2007): The Effect of Concurrent Resistance and Endurance Training on Physiological and Performance Parameters of Well Trained Endurance Cyclists, M.Sc. Thesis, School of Exercise, Biomedical, and Health Sciences, Edith Cowan University.

42. McGregor, B. (2006): The application of complex training for the development of explosive power, Journal of Strength and Conditioning Research, 14(3), pp:360.

43. Sigmon, C. (2003): 52-week basketball training, Human Kinetics

44. Smilios, I. et al. (2005): Short-term effects of selected exercise and load in contrast training on vertical jump performance, Journal of Strength and Conditioning Research, 19(1) 